\title{
Aportaciones y Límites de los Paradigmas Cognitivo y Dialógico en Educación Moral
}

\author{
XUS MARTÍN GARCÍA \\ Universidad Central de Barcelona
}

\begin{abstract}
SUMMARY. The following article tries to clarify and define the basic essentials of a particular understanding of moral education. To be exact that developed by the cognitive and dialogical paradigms in psycology and etnics respectively. Therefore the contributions of Habermas and Kohlberg will be briefly described, and some of the criticism recieved will be presented, the consideration of which can complement the original contribuionts of both authors. The aim of this process is to note down the foundations of a moral education based on the respect for personal autonomy and on the capacity to generate values of justice and solidarity.
\end{abstract}

En el presente artículo se pretenden aclarar y precisar los fundamentos de una determinada concepción de la Educación Moral. En concreto, la que ha desarrollado los paradigmas cognitivo y dialógico en psicología y ética respectivamente. Por tanto, se describirán brevemente las aportaciones de Habermas y Kohlberg, pero también se presentarán algunas de las críticas que han recibido y cuya consideración puede complementar las aportaciones originales de ambos autores. Este proceso tiene como finalidad apuntar las bases de una educación moral basada en el respeto por la autonomía personal y en la capacidad de generar valores de justicia y solidaridad.

\section{MODELOS DE EDUCACIÓN MORAL}

Los modelos educativos basados en una concepción absoluta de los valores son un intento de enfrentarse a las dificultades que conlleva la convivencia y son, asimismo, un modo de solucionarlas desde posiciones seguras y definitivas. Según esta perspectiva existe una serie de valores y normas de conducta que deben ser transmitidas de una generación a la siguiente. Son modelos educativos con clara tendencia a regular de forma minuciosa todos los aspectos de la vida personal y social, a la vez que fijan con precisión las conductas y las acciones que deben, o no, adoptar los sujetos. La imposición de los valores y normas considerados como incuestionables se lleva a cabo, generalmente, a partir de algún poder externo a la persona que el individuo reconoce como superior y digno de ser obedecido. En este tipo de modelos y de prácticas educativas, los conflictos vividos por el sujeto se sitúan siempre en relación a la coherencia entre su vida y las pautas de conducta dictadas desde el exterior. El conflicto moral interno, así como la 
responsabilidad personal para resolver conflictos no tiene gran relevancia, ya que siempre está claro qué es lo «bueno» y qué es lo «malo». El problema radica pues en la capacidad del individuo para actuar de acuerdo con la doctrina y para aceptar o no la solución propuesta por la instancia que interpreta y aplica los valores. Estos modelos implican la firme creencia en algún elemento de carácter absoluto que de manera heterónoma aporta soluciones a los diversos conflictos de valor que los sujetos pueden experimentar en su vida. La finalidad principal es la transmisión unilateral de los valores y normas que se han de respetar.

El modelo de valores absolutos perdió fuerza en la medida en que se produjo una creciente racionalización de la cultura y sociedad occidental. Racionalización que obligó a replantearse el tipo de soluciones que se daban a los problemas morales. Cuestiones tales como la felicidad, la buena convivencia o la organización social se plantearon desde una perspectiva distinta. Ni la religión ni otras visiones absolutas daban respuesta a todo ello, de modo que el proceso de desencantamiento sufrido por la sociedad acabó por facilitar la creación de las condiciones necesarias para el surgimiento de la moralidad moderna.

A raíz pues de la crisis del modelo de valores absolutos, surge un segundo modelo de educación moral basado en una concepción relativista de los valores. En términos generales podemos decir que este nuevo modelo se define por oposición al anterior. En él se considera que los valores son un tema del todo personal y que, por tanto, no se debe enseñar un determinado sistema de valores. No hay valores mejores o peores, ni normas externas que nos permitan determinar qué opción de valor es preferible a las restantes. Los conflictos de valores únicamente pueden resolverse apelando a decisiones subjetivas del individuo implicado en ellos. Cuando los conflictos de valor no son de orden privado, sino que son de ámbito público, éstos intentan analizarse y «resolverse» en función de las indicaciones e información relevante aportada por la ciencia y la técnica. Dado que los temas de valor son absolutamente personales y que están condicionados por las preferencias, gustos, emociones, maneras de pensar y circunstancias que rodean a cada individuo, el acuerdo es prácticamente imposible, y si acaso surge es fruto de la casualidad. El diálogo puede servir para comunicar opiniones y valores personales, pero no sirve como elemento de reflexión que permita buscar la mejor solución.

Los dos modelos de educación moral que hemos presentado no son los únicos posibles. Podemos imaginar un tercer modelo de educación moral basado en la construcción racional y autónoma de principios, valores y normas universales. Según estas propuestas no existen certezas absolutas que nos aporten una solución «objetiva» y segura de los problemas morales. Asimismo consideran que la ciencia o la técnica tampoco son capaces de dar soluciones a todos los conflictos de valor. Son, por tanto, propuestas alejadas de los modelos de valores absolutos pero que no se identifican con las concepciones relativistas. Este tercer modelo afirma que no todo es igualmente correcto, y que hay posibilidades basadas en la razón, el diálogo y la voluntad de valor que nos pueden permitir determinar algunos principios valiosos que, a pesar de ser abstractos y formales, pueden convertirse en guías suficientes del juicio y la conducta moral. Son propuestas que podemos calificar sus neokantianas y que defienden la razón como criterio válido para enfrentarse a los conflictos morales y para buscar buenos argumentos que permitan solucionar tales conflictos y orientar la conducta individual y colectiva ${ }^{1}$.

1. Sobre estos modelos de Educación Moral, véase Puig, M. J. y Martínez, M. (1989), Educación moral y democracia. Barcelona, Laertes, pp. 27-28. 
Es este tercer tipo de modelo de educación moral el que va a ocupar nuestra atención en el presente artículo. Para describirlo con algún detalle vamos a intentar llevar a cabo tres tareas. Primera, fundamentar dicho modelo de educación moral desde dos perspectivas disciplinarias que se complementan: la psicología y la filosofía. Y hacerlo desde la filosofía apoyándose en el paradigma de las éticas dialógicas de Apel y Habermas, y desde la psicología basándose en las aportaciones cognitivas del desarrollo del juicio moral llevadas a cabo por Piaget y sobre todo por Kohlberg. La segunda tarea que pretendemos realizar consiste en la revisión y ampliación de ambas perspectivas a la luz de algunas de las críticas que se han dirigido a cada una de ellas (crítica por no considerar los sentimientos y las emociones, crítica a la falta de contextualización del juicio moral tanto en la psicología cognitiva como en las éticas dialógicas, y crítica a la escasa claridad respecto al problema de la acción y el comportamiento moral). La tercera línea de trabajo consistirá en mostrar el paralelismo existente entre ambos paradigmas, tanto en su punto de partida como en las críticas o aportaciones complementarias que han recibido.

\section{FUNDAMENTACIÓN FILOSÓFICA DE LA EDUCACIÓN MORAL: LAS ÉTICAS DIALÓGICAS}

A comienzos de los años 70 en el ámbito de la filosofía aparece una nueva propuesta ética: la teoría de la acción comunicativa ${ }^{2}$. Los promotores de esta aportación son Apel y Habermas y su propuesta surge como réplica a algunas de las concepciones éticas vigentes. Algunas de estas concepciones son: el irracionalismo ético en el que la prioridad por la ciencia y la objetividad científica desemboca en una separación radical entre el mundo de los hechos y el mundo de los valores; el decisionismo subjetivo que considera que la normatividad moral es inargumentable, y que la voluntad no tiene argumentos ni razones para preferir una opción sobre otra; y el individualismo metódico que trata de mantenerse en la neutralidad axiológica, limitándose a confrontar al individuo con las posibles alternativas. Frente a tales posturas, las éticas comunicativas descubren el carácter intersubjetivo y dialógico de la formación de la conciencia moral.

Como respuesta a las insuficiencias evidenciadas en estos modelos, surge la propuesta de Apel y Habermas. Estos autores defienden una nueva teoría de la racionalidad: una teoría consensual de la verdad y la corrección. Consideran que las normas morales pueden y deben ser argumentadas, y que es deseable que la argumentación tenga un valor universal, dado que con frecuencia los problemas son colectivos. No bastaría, pues, con una validez únicamente individual, sino que las normas deberían servir y ser compartidas por todos los implicados en un conflicto ${ }^{3}$.

Podríamos definir esta propuesta como neokantiana dado que su origen está en las posiciones defendidas por Kant. Sin embargo, la aportación de éste sufre modificaciones

2. Apel y Habermas designan a esta ética con varios nombres: ética dialógica, discursiva, comunicativa o ética de la responsabilidad solidaria.

3. Apel, K. O. (1991), Teoría de la verdad y ética del discurso. Barcelona, Paidós/I.C.E.UAB. (1986), Estudios éticos. Barcelona, Alfa. Ferry, J. M. (1987), Habermas, l'ethique de la communication. París, PUF. McCarthy, T. (1987), La Teoría Crítica de Jürgen Habermas. Madrid, Tecnos. Habermas, J. (1985), Conciencia moral y acción comunicativa. Barcelona, Península. (1991), Escritos sobre moralidad y eticidad. Barcelona, Paidós/I.C.E.-UAB. 
sustanciales. En la teoría de la acción comunicativa el concepto de persona defendido por Kant, que insistía en el valor de la conciencia individual, se transforma en la idea de persona como ser dotado de capacidad comunicativa, a quien nadie puede privar de su derecho a defender sus pretensiones racionales mediante el diálogo. La ética comunicativa entiende que las cuestiones prácticas pueden ser decididas racionalmente. La razón, por tanto, puede aportar argumentos suficientes, o buenos argumentos para resolver conflictos de valor y para guiar la conducta humana. Esta razón no es puramente individual ni permanece cerrada en el sujeto, sino que es construida de forma dialógica. Finalmente, la función que Apel designa prioritariamente a la teoría de la acción comunicativa es la de dirigir indirectamente la acción. Esta función se lleva a cabo atendiendo dos facetas complementarias. Por una parte se debe fundamentar racionalmente el principio ético, y por otra buscar el marco formal necesario para aplicar a la acción tal principio ${ }^{4}$.

\section{Habermas: El lenguaje y su uso consensual}

En su afán por definir un criterio legítimo que fundamente la teoría de la acción comunicativa, Habermas recupera el lenguaje y su uso consensual. La preocupación por el lenguaje se debe al supuesto de que en éste se da profundamente una tendencia al entendimiento y el consenso. Habermas señala, sin embargo, los diferentes modos de usar el lenguaje. Unio, aquel que busca el acuerdo, que se orienta al entendimiento. Dos, el lenguaje que podríamos definir como «estratégico», aquel que prioriza los intereses de uno de los implicados en detrimento del resto. Sólo el primer uso del lenguaje es el que puede fundamentar la ética discursiva. Como indicábamos anteriormente la filosofía kantiana basada en la conciencia es sustituida por una filosofía basada en la comunicación y la intersubjetividad que se manifiesta a través del lenguaje y el diálogo.

El diálogo y la razón son pues elementos que se funden en la propuesta ética de Apel y Habermas. La razón dialógica como elemento principal de dicha teoría supone que son rectos aquellos principios y normas que se han conseguido por medio de un acuerdo basado en las mejores razones, expresadas entre todos los participantes o afectados en el conflicto $^{5}$. En tal sentido, la razón dialógica expresada en la comunidad ideal de diálogo sólo se manifiesta cuando:

- se parte de un conflicto de acción identificado en común, así como de una cierta identidad de significados que permite dar sentidos parecidos a las mismas cosas;

- en los implicados se da una voluntad de intersubjetividad y de comprometerse en un proceso de diálogo;

- todos los participantes pueden argumentar y expresarse libremente de modo que no haya coacción y estén en pie de igualdad;

- en el diálogo se tienen en cuenta tanto los propios intereses, deseos, puntos de vista, sentimientos y necesidades, como los intereses, puntos de vista, deseos y sentimientos de todos los implicados en la situación;

4. Cortina, A. (1989), «La ética discursiva» en Camps, V. (comp.), Historia de la ética. 3. La ética contemporánea. Barcelona, Crítica, p. 534.

5. Habermas, J. (1989), Teoría de la acción comunicativa: Complementos y estudios previos. Madrid, Cátedra, pp. 161-229. 
- el diálogo está orientado a la obtención intencional y voluntaria de un acuerdo basado en las mejores razones. Acuerdo alcanzado comunicativamente y que surge principalmente en el círculo de los afectados. El fin a conseguir es el acuerdo racionalmente motivado, alcanzado mediante el ejercicio de la libre argumentación y con la sola coacción de las mejores razones;

- se busca un acuerdo generalizable que entiende a la persona (a todas) como fines y no como medios ${ }^{6}$.

La lógica del discurso práctico, que argumenta acerca de la corrección de las normas, constituye la clave de la ética discursiva: describir aquellas reglas, aquellos presupuestos que cualquier participante en un discurso los ha reconocido ya implícitamente.

Es por todo ello que, desde la ética dialógica o discursiva, una norma sólo será aceptada si vale el principio de universalización, principio que lleva incorporado el consensualismo. Es decir, si se ha conseguido gracias a un acuerdo racionalmente motivado, producido en una situación ideal de diálogo. La voluntad racional, lo que «todos podrían querer» sigue siendo el criterio para legitimar normas morales. El discurso práctico lo que realmente posibilita es examinar la generabilidad de los intereses. Cuando se alcanza un consenso acerca de la recomendación de aceptar una norma, y se logra en el intercambio de argumentos, ese consenso expresa entonces una voluntad racional. Podemos llamar racional a la voluntad formada discursivamente ${ }^{7}$.

Estamos pues ante una ética cognitivista, deontológica, formal y universalista. Es una ética cognitivista por cuanto considera que los juicios morales tienen un contenido racional que permite distinguir juicios morales más o menos óptimos. Defiende asimismo que los conflictos morales pueden solucionarse mediante razones, y que, a partir de las investigaciones de Kohlberg, es posible determinar el grado de madurez de los razonamientos morales, es decir, es posible distinguir las mejores razones ${ }^{8}$. Es también una ética deontológica en la medida en que se ocupa de la vertiente normativa del fenómeno moral y prescinde de las cuestiones referentes a la felicidad y la vida buena. Entiende que es necesario un mínimo normativo universal para posibilitar el pluralismo de las formas de vida ${ }^{9}$. Sin embargo, no pretende determinar lo que es bueno ni tienen como objeto facilitar orientaciones sobre el contenido moral, coincidiendo en ello con éticas deontológicas como la de Rawls o Kohlberg. Su función es proporcionar pautas, criterios o procedimientos para juzgar la aceptabilidad de las normas. En este sentido la podemos

6. Berkowitz, M. W. (1985), «The Role of Discussion in Moral Education» en Berkowitz, M. W. y Oser, F., Moral Education: Theory and Application. London, LEA, pp. 197-218. Grice, H. P. (1975), «Logic and conversation» en Cole, P. y Morgan, J. (edits.), Syntax and Semantics. Vol. 3, Speech Acts. New York, Academic Press, pp. 41-58. Habermas, J. (1987), Teoría de la acción comunicativa. Madrid, Taurus. Habermas, J. (1989), Teoría de la acción comunicativa. Complementos y estudios previos. Madrid, Cátedra. Levisnton, S. C. (1989), Pragmática. Barcelona, Teide. Puig, J. M. (1993), Toma de conciencia de las habilidades para el diálogo. Madrid, Didácticas CL \& E, pp. 12-14, 68-70. 68.

7. Habermas, J. (1991), Escritos sobre moralidad y eticidad. Barcelona, Paidós/ICE-AUB, p. 142.

8. Habermas, J. (1985), Conciencia moral y acción comunicativa. Barcelona, Edicions 62, p.

9. Cortina, A. (1989), «La ética discursiva» en Camps, V. (comp.), Historia de la ética. 3. La ética contemporánea. Barcelona, Crítica, p. 552. 
considerar una ética procedimental ${ }^{10}$. Es, en tercer lugar, una ética formal porque a pesar de defender unos valores (diálogo, consenso, solidaridad, etc.) no determina normas concretas de conducta ni define la manera de aplicar los principios formales y abstractos en cada realidad histórica concreta, por cuanto lo considera contenido no susceptible de universalización. Por último, la ética discursiva se caracteriza como ética universal. El universalismo se plantea, no como principio moral, sino como regla de argumentación utilizada para comprobar en qué medida el principio ético se aplica de forma correcta. Regla de argumentación que da lugar también a un mínimo de intersubjetividad que permite respetar la diversidad propia de la experiencia democrática. No puede entenderse, por tanto, como principio de homogeneidad. La libre argumentación, la no coacción y el derecho de cada participante a expresarse, características todas ellas necesarias para iniciar el discurso práctico, son elementos potenciadores de la contradicción y la diferencia y garantizan el respeto hacia formas de vida y culturas diferentes ${ }^{11}$. El postulado de la universalidad implica a su vez un rechazo hacia los supuestos teóricos de las éticas relativistas, insistiendo en la existencia de vías evolutivas de carácter general que pueden y deben ser recogidas en una teoría del desarrollo moral ${ }^{12}$.

Pese a la importancia de las éticas comunicativas, consideramos que puede ser criticada y completada por aspectos que en ella aparecen escasamente tratados.

\section{Las emociones y los sentimientos en la reflexión moral}

Los sentimientos y las emociones son elementos poco desarrollados en la propuesta de Apel y Habermas, sin que ello implique que estén olvidados o rechazados dentro del paradigma dialógico. Los promotores de la ética discursiva son conscientes de que tales elementos tienen una clara repercusión en el desarrollo del juicio y la conducta moral. El mismo Habermas se pronuncia a favor de los sentimientos morales, reconociendo la función de éstos en relación a los fenómenos morales, pero manifestando también su limitación y los riesgos que puede conllevar priorizarlos por encima del juicio moral. La función que Habermas otorga a las emociones y sentimientos es la sensibilización para los fenómenos morales y la relevancia que tienen en la aplicación, fundamentación y consolidación de las normas. Los sentimientos y emociones morales son básicos en el desarrollo de la sensitividad o capacidad del sujeto para percibir y reconocer conflictos y problemas morales, desempeñando por ello un importante papel en la constitución de los fenómenos morales. El «sentir» que la integridad de una persona está amenazada o no ha sido respetada fomenta el reconocimiento de determinados conflictos como moralmente relevantes. Dicha sensibilidad es necesaria e imprescindible para descubrir e iniciarse en el amplio y complejo terreno de lo moral. Los sentimientos morales, a su vez, proporcionan al individuo una orientación y un enfoque en el momento de enjuiciar una

10. Habermas, J. (1985), Conciencia moral y acción comunicativa. Barcelona, Edicions 62, p. 143.

11. Cortina, A. (1989), «La ética discursiva» en Camps, V. (comp.), Historia de la ética. 3. La ética contemporánea. Barcelona, Crítica, p. 559.

12. Habermas, J. (1985), Conciencia moral y acción comunicativa. Barcelona, Edicions 62, p. 142. 
situación particular, considerada como moralmente relevante. Es por ello que podemos considerar que los sentimientos constituyen el tipo de experiencia sobre el que se basan los primeros juicios intuitivos. Los diferentes sentimientos morales (de vergüenza, de dolor, de rabia, etc.) son habitualmente reacciones a perturbaciones que tienen lugar en las relaciones interpersonales o en el reconocimiento intersubjetivo.

Junto a la importancia que tienen los sentimientos morales en los primeros juicios intuitivos y en la aplicación de las normas, también podemos señalar el papel de éstos en la fundamentación de las mismas. La empatía o capacidad para ponerse en circunstancias distintas a la propia y difíciles de entender, superando distancias culturales y diferencias en relación a formas de vida y de interpretación de los hechos, es una condición emocional básica para la asunción de roles que lleva a cada uno a asumir la perspectiva de todos los demás. Recordemos que la asunción de roles y el ponerse en el lugar del otro son capacidades que se exigen a una personalidad moral madura.

Si bien, como hemos visto, desde el paradigma dialógico se otorga un papel a los sentimientos morales, también es cierto que sus autores explicitan de forma clara y contundente que éstos no deben ser el elemento decisivo o criterio prioritario en el enjuiciamiento y toma de decisiones. Dejar tales aspectos a merced de los sentimientos espontáneos haría todavía más frágil la idea de igualdad entre los seres humanos. El juicio moral, debe ser en definitiva, la instancia última a la cual recurrir si queremos salvaguardar los ideales de justicia, igualdad y solidaridad ${ }^{13}$. No cabe duda que gracias a los sentimientos morales empezamos a sensibilizarnos respecto de los fenómenos morales; y en cuanto a las cuestiones de fundamentación de normas y de su aplicación, cumplen además una inapreciable labor heurística. Pero en lo tocante al enjuiciamiento de los fenómenos que esos sentimientos abre, éstos no pueden ser la última instancia.

En síntesis, de las aportaciones de Habermas se deriva una separación importante entre sentimientos y razones. Si bien valora el papel de los sentimientos en el ámbito moral, también es cierto que éstos aparecen supeditados al razonamiento y el juicio moral. Esta separación establecida o deducida de los comentarios de Habermas no es generalmente compartida. La relación racionalidad-emotividad es un dilema que ha perdurado a lo largo de la historia del pensamiento ético y cuya polémica permanece abierta en el momento presente.

En oposición a las interpretaciones que sitúan racionalismo y emotivismo como polos antagónicos, se da una serie de aportaciones que defienden la síntesis de ambos, entendiendo que son aspectos inseparables de los enunciados éticos en la medida tienen un carácter emotivo y valorativo, sin dejar por ello de ser racionales. Asimismo se entiende que el aspecto emotivo o afectivo de los enunciados éticos viene determinado por la carga racional y la fuerza moral que conllevan ${ }^{14}$. Es por ello que no basta con que la persona considere una postura o acción como «buena», sino que la postura en cuestión ha de ser digna de ser considerada como tal, y por tanto, debe haber razones para considerarla

13. Habermas, J. (1991), La necesidad de revisión de la izquierda. Madrid, Tecnos, p. 206-207.

14. Benhabib, S., «Una revisión del debate sobre las mujeres y la teoría moral», en ISEGORIA, $\mathrm{n}^{\circ}$ 6, noviembre 1992. Guisan, E. (1986), Razón y pasión en ética. Los dilemas de la ética contemporánea. Barcelona, Anthropos, p. 208-224. Nicholson, L. (ed.) (1990), Feminism/Postmodernism. New York/London, Routledge. Valcarcel, A. (1991), Sexo y filosofía. Sobre mujer y poder. Barcelona, Anthropos. 
de esa manera. Son precisamente estas razones y argumentos las que constituyen la fuerza moral de los enunciados éticos. Es esta una postura lejana y opuesta al emotivismo clásico, que niega la posibilidad de diálogo en términos éticos, reduciéndolo a un estricto subjetivismo y negando toda posibilidad de conocimiento. Contrariamente a esta visión individualista del pensamiento ético, se subraya la importancia del lenguaje moral como medio de comunicación, es decir, como instrumento que nos permite influir y dejarnos influir por los demás.

Intentando superar la fisura en la relación emotivismo-racionalismo, planteada desde la perspectiva emotivista clásica, aparece el «Método de la actitud cualificada» de Brandt ${ }^{15}$. En él se presenta la razón como elemento que ayuda a tomar decisiones, y la afectividad (actitud, deseos, intereses, etc.) como ámbito que es reconducido por la razón. La necesidad de reconocer el elemento emotivo en los juicios éticos, así como la necesidad de disponer de un método para utilizar unos principios que equilibren la visión subjetiva de los hechos, son puntos básicos de esta teoría. El segundo supuesto, nos acerca a la idea de principios universales defendida por Habermas y Kohlberg, y a la importancia de procedimientos o pautas que guíen, pero no determinen el juicio y la conducta moral. El método de la actitud cualificada garantiza la posibilidad de diálogo en la discusión ética a la vez que respeta la diferencia, la creatividad y la existencia de soluciones personales y autónomas a los problemas éticos. En esta misma línea, y muy próxima a la ética comunicativa de Habermas encontramos la propuesta de Hare ${ }^{16}$, donde se defienden los supuestos de emotividad y prescriptividad y se afirma que la función de la ética consiste en unir y equilibrar las diferentes actitudes e intereses con principios imparciales. Estos principios o preferencias tendrían el carácter de universales y no consistirían en intereses individuales armonizados sino en intereses nacidos de la interacción con los intereses de los demás.

Hemos visto, a partir de estas aportaciones, como la cuestión de la afectividad preocupa y cómo puede incluirse en la filosofía ética. Podemos concluir subrayando la importancia de vincular racionalidad y emotividad, entendiendo que ambas no sólo se complementan sino que se optimizan mutuamente. Insistimos también en que son propuestas no contradictorias con la ética comunicativa de Habermas y que distintos autores han hecho referencia a la necesidad de principios o preferencias universales que permitan y aseguren el diálogo sobre temas éticos.

\section{La contextualización de los criterios de reflexión moral}

Un segundo elemento poco explicitado, pero coherente con los principios de la ética discursiva es el referente a la construcción de criterios morales contextuales. Como explicamos anteriormente, los principios y normas a los que se refieren las éticas dialógicas son de carácter universal, abstracto, formal y procedimental. No indican normas de actuación ni enjuiciamiento concreto, y por tanto, si bien son una orientación válida e interesante, no sirven de modo inmediato para resolver los conflictos de valor con que

15. Brandt, R. B. (1982), Teoría ética. Alianza, Madrid.

16. Hare, R. M. (1981), Moral Thinking. Oxford University Press. 
los sujetos se encuentran cotidianamente. Esta «limitación» ${ }^{17}$ de los principios universales pone de manifiesto la necesidad de crear normas morales contextualizadas y referidas a las condiciones de vida reales de las distintas comunidades e individuos, es decir, la necesidad de traducir la metanorma moral a normas morales concretas y situadas en el contexto histórico-social («eticidad»). Tanto Apel como Habermas insisten en la necesidad de llevar a cabo dicha traducción. Traducción que no se consigue deduciendo mecánica y directamente normas morales a partir de los principios universales y que, por tanto, es falible y requiere de una serie de condiciones que garanticen al máximo posible la presencia de los principios universales característicos de la ética dialógica ${ }^{18}$.

La primera condición para llevar a cabo la traducción de la metanorma a las normas concretas, consiste en la utilización de una metodología constructivo-dialógica que incluya la participación de todos los afectados y proteja su derecho a expresarse libremente. Se trata de encarnar, en la comunidad real y concreta, la comunidad ideal de diálogo defendida desde la ética discursiva ${ }^{19}$. Una segunda condición consiste en compaginar o equilibrar las exigencias de la «ética de convicciones» y de la «ética de responsabilidad», exigencias que con frecuencia se presentan como contradictorias. El reclamo de tal equilibrio consiste en hacer compatibles los principios morales y los juicios responsables que reconozcan y asuman las consecuencias de la decisión que establecen. Los conflictos entre las exigencias de ambas éticas siempre surgen cuando los principios deben ser aplicados a una situación concreta. Priorizar una ética de convicciones en detrimento de la ética de responsabilidad lleva a adoptar medidas unilaterales, poco contextualizadas y desvinculadas de la situación a la que se aplican, es decir, medidas irresponsables. Por otra parte, prescindir de la ética de principios en situaciones de conflicto dejaría la decisión o solución a merced únicamente de opiniones, sentimientos o vivencias puntuales y esporádicas. Es decir, nos encontraríamos bajo una moral relativista e individualista. La tercera condición reside en la necesidad de salvaguardar el pluralismo y el derecho a la diferencia. Dado el carácter de falibilidad de la traducción contextualizada de la metanorma, es inevitable que se produzcan interpretaciones y normas concretas distintas, incluso contrapuestas. $\mathrm{Si}$ la traducción se ha realizado mediante un procedimiento constructivo-dialógico y se ha respetado las condiciones para legitimar una norma moral, esto es autonomía y universalizabilidad, el disenso es tan legítimo como el acuerdo. Estas situaciones de pluralismo ético son especialmente previsibles cuando se trata de enjuiciar o traducir normas en relación a temas conflictivos y complejos. La cuarta y última condición, gira en torno a la elección individual, expresión máxima de la autonomía del sujeto moral. Es este un aspecto poco tratado explícitamente en las aportaciones de Apel y Habermas. La prioridad que desde la ética discursiva se da al logro del con-

17. Cortina, A. (1985), «El contexto filosófico de la respuesta» en Moral y eticidad. De los límites extremos de toda filosofía práctica. Salamanca, Sígueme, p. 224.

18. Para tratar estos aspectos nos hemos basado principalmente en la obra de Gadamer. Gadamer, H. G. (1991), «Sur la possibilité d'une Ethique philosophique» en Gadamer, H. G., L'art de comprendre. Ecrits II. París, Aubier, pp. 311-328. (1988), Verdad y método. Salamanca, Sígueme. (1993), El problema de la conciencia histórica. Madrid, Tecnos. En nuestro país, Rubio Carracedo ha desarrollado con precisión y amplitud estos temas. Rubio Carracedo, J. (1992), Etica constructiva y autonomía personal. Madrid, Tecnos, pp. 35-37, 254-278.

19. Apel, K. O. (1991), Teoría de la verdad y ética del discurso. Barcelona, Paidós, p. 157. 
senso entre todos los afectados, deja en un segundo plano la riqueza que el disenso puede aportar, teniendo en cuenta que la traducción a normas contextuales es siempre falible y que por tanto, puede haber más de una solución justa y deseable. Es por ello que después de haber participado en el discurso ético y haber respetado las condiciones de diálogo, el sujeto debe elegir y decidir de forma autónoma, reconociendo y respetando a la vez, la capacidad ética de los demás y su derecho a tomar una decisión diferente.

\section{El comportamiento moral y las virtudes en la perspectiva de la ética dialógica}

Un último aspecto poco explícito en el paradigma dialógico es el tema del carácter o personalidad moral, así como los elementos que de ahí se derivan (actos, hábitos y virtudes morales). Si bien los promotores de la ética discursiva no le han dedicado un espacio significativo en sus reflexiones, esta perspectivas moral lleva implícita en sí misma una propuesta de carácter y virtudes morales, tal como han señalado otros filósofos intentando complementar las aportaciones de la ética discursiva ${ }^{20}$.

El carácter deontológico de la ética discursiva la hace aparecer como excesivamente formal, abstracta y distanciada de los hábitos, valores y actitudes que desde un punto de vista moral pueden ser considerados como deseables. El hecho de estar basada en principios universales parece enfrentarla con una ética de actitudes, más preocupada por los hábitos, las disposiciones y las virtudes. Esta separación, sin embargo, nos parece algo forzada. La ética de principios no tiene porque entenderse como esencialmente distinta y contrapuesta a una ética de actitudes. Es más, consideramos que en la ética discursiva late ya una propuesta de ethos moral.

El punto de partida de la ética dialógica, esto es la búsqueda de acuerdo en la discusión y la disponibilidad hacia la solución dialogada de conflictos, implica ya una forma de vida que encierra en sí valores y actitudes. Es, por tanto, una propuesta de ethos universalizable que viene definido por una serie de rasgos. Estos son: la actitud de autorrenuncia ante los propios intereses y convicciones que esconderían la verdad si se impusieran como únicos; el reconocimiento del derecho de los miembros de la comunicación real de investigadores a exponer sus propios hallazgos y de la obligación, ante ellos, de justificar los propios descubrimientos; el compromiso moral en la búsqueda de la verdad; y, por último, la esperanza en el consenso definitivo, que es crítica y garantía de los consensos fácticos y, que debe ser solidariamente realizado ${ }^{21}$. El ethos dialógico que se propone como universalizable coincide con un ethos democrático, que supone el cultivo de un estilo de vida, unos hábitos y unas virtudes. Vemos pues como la ética de principios necesita de una serie de actitudes concretas que la posibiliten. Principios y actitudes no aparecen ya como elementos que se excluyen, sino que se complementan y reclaman.

20. En este sentido es relevante el libro de Cortina, A. (1990), Etica sin moral. Madrid, Tecnos, especialmente las pp. 219-238, 254-272.

21. Cortina, A. (1990), Etica sin moral. Madrid, Tecnos, pp. 237-238. Cortina, A. (1989), «La ética discursiva» en Camps, V. (comp.), Historia de la ética. 3. La ética contemporánea. Barcelona, Crítica, pp. 556. 
A pesar de la importancia y validez del ethos dialógico o democrático es necesario darle una orientación más abstracta, formal y universalizable. Con ello apuntamos a la importancia que los procesos de autorregulación personal pueden y deben tener en la construcción del carácter moral. Pensamos que junto a la moral de principios y a las actitudes derivadas de una ética dialógica, cada sujeto debe constituirse en el principal responsable de su vida. Esto posiblemente se lleve a cabo en un doble sentido. En primer lugar, el sujeto se construye y modela en tanto que se trabaja y actúa sobre sí mismo. Las tecnologías del yo estudiadas por Foucault tendrían aquí un papel relevante ${ }^{22}$. En segundo lugar, el sujeto se modela diseñando mentalmente una forma de ser deseada, un modelo de ser personal. Sin embargo, subrayar la capacidad del individuo para autogobernarse y lograr el modo deseado de existencia no debe entenderse en oposición a la aceptación de la metanorma moral ni como defensa acérrima del individualismo y el relativismo moral. Pensamos que en este sentido, Foucault exagera al presentar como incompatibles la búsqueda de una ética personal con una moral universal ${ }^{23}$. El proceso de construcción personal, construcción de hábitos, virtudes y un modo de ser, lo debemos entender como un proceso autónomo, pero a su vez compatible e integrado en la ética de principios de la que hablábamos anteriormente.

FUNDAMENTACIÓN PSICOLÓGICA DE LA EDUCACIÓN MORAL: LAS TEORÍAS COGNITIVAS DEL DESARROLLO MORAL

Apel y Habermas elaboran y plantean su propuesta ética como respuesta a la ruptura de los acuerdos sociales convencionales, paralelamente las propuestas cognitivas del desarrollo moral pueden entenderse como respuesta o alternativa a la educación moral como socialización. Las teorías de la socialización defienden el desarrollo moral como adaptación heterónoma del individuo a la sociedad. El sujeto, según estas teorías, debe limitarse a asumir las influencias que recibe del exterior, prescindiendo, en gran medida, de sus capacidades cognitivas y de su autonomía. En contraposición y casi como respuesta a esta concepción de la formación moral, surgen las propuestas cognitivas del desarrollo moral. Estas entienden el desarrollo moral como la progresiva construcción de un pensamiento moral autónomo, lo cual no es únicamente un proceso individual, pero tampoco depende exclusivamente del medio, sino que se consigue en continua interacción con él. El sujeto no pierde así su autonomía, conservando un importante papel autorganizador en su propio desarrollo ${ }^{24}$.

De la misma manera que al hablar de la fundamentación filosófica nos situamos en el paradigma de las éticas dialógicas e hicimos una presentación de sus rasgos más característicos y de aquellos elementos que a nuestro juicio la podían complementar, desde la psicología partiremos del paradigma cognitivista del desarrollo sociomoral, introduciendo nuevas aportaciones que de forma no contradictoria enriquecen las teorías del

22. Foucault, M. (1990), Tecnologías del yo. Barcelona, Paidós/ICE/UAB.

23. McCarthy, T., «Filosofía y teoría crítica en los Estados Unidos. Foucault y la Escuela de Francfort», en ISEGORIA, $\mathrm{n}^{\circ} 1$, mayo, 1990, p. 76.

24. Durkheim, E. (1947), La educación moral. Buenos Aires, Losada, p. 30. Piaget, J. (1987), El criterio moral en el niño. Barcelona, Martínez-Roca, p. 341. 
desarrollo moral. Nos centraremos en la aportación de Kohlberg por considerarla lo más explícita y significativa, aunque no sea el único autor relevante.

\section{Kohlberg: hacia el juicio moral postconvencional}

Si bien los trabajos realizados por Piaget respecto al desarrollo moral supusieron una aportación importante y novedosa en el ámbito de la psicología moral, es Lawrence Kohlberg quien elaboró con mayor precisión una teoría del desarrollo del juicio moral ${ }^{25}$. Las investigaciones de Kohlberg parten, por tanto, de los trabajos realizados por Piaget y de las tesis defendidas por éste en su obra «El criterio moral en el niño». Los descubrimientos realizados por Piaget sobre la existencia de distintas etapas de desarrollo moral, etapas «universales y regulares» y con base formal-cognitiva son el punto de arranque de los estudios empíricos y prácticos llevados a cabo por Kohlberg. En su tesis doctoral defendida en 1958 , «El desarrollo de los modos de pensamiento y opción moral entre los diez y los dieciséis años», se encuentran ya plasmadas las ideas principales que en trabajos posteriores serán ampliamente comprobadas y estudiadas. En ella Kohlberg trata, desde la perspectiva del desarrollo cognitivo, las sucesivas manifestaciones del juicio moral. Su idea fundamental es que existe un desarrollo «natural» en el pensamiento moral que se sucede a través de seis estadios progresivos y consecutivos, independientemente de cada cultura. La contribución de Kohlberg con su tesis doctoral y con los trabajos que la continuaron fue aplicar el concepto de desarrollo por estadios al juicio moral. Los estudios e investigaciones de Kohlberg quedan pues centrados en el desarrollo del juicio moral, es decir, en la capacidad del sujeto para razonar respecto a temas morales. Ante una situación conflictiva o un dilema moral, el sujeto produce razones, argumenta con la finalidad de defender su propio punto de vista. Estas razones responden a distintos criterios que la persona utiliza porque considera válidos y defendibles. Son criterios que permiten al individuo diferenciar lo que está bien de lo que está mal y le ayudan solucionar situaciones moralmente controvertidas. Podemos decir que son estos criterios lo que constituye la forma básica de los estadios del desarrollo de juicio moral para Kohlberg. La preocupación de éste no es el contenido concreto de valor, sino las formas propias del razonamiento: es decir, la estructura del juicio moral. El ejercicio del juicio moral es, por tanto, un proceso cognitivo que permite al sujeto reflexionar sobre sus propios valores y ordenarlos jerárquicamente. Los trabajos realizados por Kohlberg a lo largo de los veinte años que dedicó a investigar el tema demuestran la existencia de seis grandes estructuras de razonamiento moral que las personas pueden desarrollar a fin de solucionar de modo cada vez más complejo y óptimo los conflictos de valor.

25. Kohlberg, L. (1992), Psicología del desarrollo moral. Bilbao, Desclée de Brouwer (1981), Essays on moral development. Volume 1. The Philosophy of moral Development. San Francisco, Harper and Row. Colby \& Kohlberg, L. (1987), The Measurement of moral Judgment. New York, Cambridge University Press. Hers, R.; Reimer, J. y Paolitto, D. (1984), El crecimiento moral de Piaget a Kohlberg. Madrid, Narcea. Powers, F. C.; Higgins, A. y Kohlberg, L. (1989), Lawrence Kohlberg's. Approach to Moral Education. New York, Columbia University Press. 
Entre los factores que posibilitan el desarrollo del juicio moral Kohlberg señala fundamentalmente dos: el desarrollo cognitivo o intelectual y la perspectiva social. El nivel de desarrollo cognitivo condiciona y delimita no sólo el estadio de juicio moral, sino también el grado de empatía o la capacidad para asumir roles. La perspectiva social o capacidad para asumir el rol de otro es una habilidad social que se desarrolla gradualmente desde la edad de seis años y que es un factor decisivo en el crecimiento del juicio moral. Estos elementos son necesarios pero no suficientes para que se dé el desarrollo del juicio moral. Es decir, la inmadurez de alguno de ellos impedirá avanzar de un estadio moral a otro, pero su existencia no garantiza el desarrollo del razonamiento moral ${ }^{26}$.

Respecto al contenido que se estructura en cada uno de los seis estadios o modos de pensamiento, cabe señalar que es un contenido cognitivo, formal y universal. Es cognitivo en la medida en que los conflictos morales son planteados desde el punto de vista racional. La existencia de sentimientos o preferencias no invalida el supuesto de que los juicios morales deben ser defendidos mediante razones. Es un contenido formal por cuanto la optimización o desarrollo del juicio moral hace referencia al tipo de razonamiento y no al contenido concreto del razonamiento. Los estadios no se ocupan de normas concretas sino de principios generales y criterios de razonamiento. Estos principios generales quieren ejercer una función de guía para que cada persona o colectivo pueda derivar a partir de ellos aquellas normas que considere más oportunas y válidas a una situación determinada. Podemos considerarlo un contenido universal porque según Kohlberg en todas las culturas y subculturas del mundo se encuentran los mismos valores morales básicos y los mismos estadios hacia una madurez moral. A pesar de que los diferentes ambientes produzcan directamente distintas creencias específicas, no por ello generan distintos principios morales básicos.

En su propuesta concreta del desarrollo del juicio moral Kohlberg establece tres niveles básicos de razonamiento moral cada uno de los cuales agrupa dos estadios cuya forma de razonamiento es similar, si bien hay una diferenciación en el grado de optimización o perfeccionamiento. Mientras que los niveles definen enfoques en la resolución de los problemas morales, los estadios definen los criterios por los que el sujeto ejercita su juicio moral. Cada nivel de juicio moral implica básicamente tres aspectos. Uno, los modos generales de definir lo que es bueno y de valorar las situaciones; dos, el tipo de razones que se utilizan para defender la percepción de «lo bueno»; y tres, la perspectiva social del estadio. Los niveles son: el preconvencional, el convencional y el postconvencional $^{27}$.

En el nivel preconvencional se encuentran habitualmente los niños y niñas de cinco a catorce años y en él todavía no se da una comprensión o apreciación de las reglas sociales y de la autoridad. Las cuestiones morales son planteadas teniendo en cuenta únicamente los intereses de las personas implicadas. En el primer estadio el egocentrismo impide al sujeto considerar los intereses psicológicos de los demás, limitándose a valorar

26. Kohlberg, L. (1987), «El enfoque cognitivo-evolutivo de la educación moral» en Jordán, J. A. y Santolaria, F. (comps.), La educación moral hoy, cuestiones y perspectivas, pp. 87. Kohlberg, L. (1992), «Estadio y secuencia: vía cognitivo-evolutiva a la socialización», en Kohlberg, L., Psicología del desarrollo moral. Bilbao, Desclée de Brower, pp. 55-58.

27. Kohlberg, L. (1992), «Estadios morales y moralización: la vía cognitivo-evolutiva», en Kohlberg, L., Psicología del desarrollo moral. Bilbao, Desclée de Brower, pp. 185-193. 
la bondad o maldad de la acción por las consecuencias físicas que de ella se derivan. El paso al segundo estadio supone el reconocimiento de la existencia de intereses individuales distintos. Lo correcto es satisfacer las propias necesidades y permitir a los demás hacer lo mismo. Encontramos aquí el concepto de justicia en términos de igualdad cuantitativa en cuanto que expresa la idea de intercambio de favores entre los individuos ${ }^{28}$.

El paso del nivel preconvencional al nivel convencional requiere que el sujeto se inicie en el dominio de las relaciones formales. Al nivel convencional se suele llegar en los años de la adolescencia y en muchos casos se permanece en él durante toda la vida. En esta etapa el individuo emite juicios tomando como única referencia las reglas y las expectativas que el grupo tiene sobre él. Los temas morales se plantean desde la perspectiva que da el sentirse miembro de un grupo social. En un primer momento, el estadio tres, las razones para actuar de forma justa se refieren a la aprobación por parte de las personas más allegadas y apreciadas. En el estadio cuatro el grupo de referencia se amplia a la sociedad. Lo correcto consiste en cumplir con los propios deberes, defender las leyes sociales, mostrar respeto por la autoridad y mantener el orden social establecido, que es considerado como un valor en sí mismo. Las leyes y roles son consideradas justas por definición, mientras no entren en conflicto con otras leyes sociales fijas, y se entiende que éstas garantizan la justicia y la igualdad entre todas las personas.

En el nivel postconvencional, el individuo entiende las reglas de la sociedad pero no queda limitado a ellas. El pensamiento se rige aquí por principios y no por reglas sociales. Estas serán aceptadas en la medida que se fundamenten en principios y valores generales. En el estadio cinco, el consenso y el diálogo como procedimiento de organización social se imponen por encima de las normas concretas. Se supera así la mentalidad legalista del estadio anterior, aportando el mecanismo de la democracia y la posibilidad de cambiar las leyes establecidas. El sujeto que se encuentra en el último estadio, estadio seis, considera a cada persona como un fin y no como un medio, de tal forma que los derechos de cada ser humano son inviolables aunque no estén codificados en una ley concreta. Los temas morales se enfocan desde una perspectiva superior a la sociedad $^{29}$.

Al igual que ocurrió en la parte dedicada a la fundamentación filosófica del currículum, nos encontramos que hay aspectos omitidos o poco elaborados en las investigaciones de Kohlberg. Sin entrar en contradicción con sus supuestos básicos, existen distintas aportaciones que han querido introducir elementos complementarios que enriquecen y optimizan las tesis elaboradas por tales autores respecto al desarrollo del juicio moral.

\section{Justicia y cuidado: la presencia del sentimiento en el juicio moral}

Uno de los aspectos que con frecuencia ha acumulado mayor número de críticas dentro de las posturas cognitivas ha sido su escasa sensibilidad y preocupación hacia el tema de las emociones y los sentimientos. La importancia de la afectividad se ha visto

28. Kohlberg, L., «From Is to Ought», en Kohlberg, L. (1981), Essays on moral development. Volume 1. The Pilosophy of moral Development. San Francisco, Harper and Row, pp. 101-189.

29. Kohlberg, L., «Estadios morales y moralización. La vía cognitivo-evolutiva» en Kohlberg, L., Psicología del desarrollo moral. Bilbao, Desclée de Brower, p. 187. 
relegada a un segundo plano, cuando no omitida, en las teorías cognitivas. Esta crítica habitual toma un giro profundo e interesante a partir de las críticas feministas a la aportación de Kohlberg. El esfuerzo por diferenciar la moral femenina de la moral masculina pone de relieve la importancia que los sentimientos y las emociones ejercen en el juicio moral.

Probablemente fue Carol Gilligan con su libro «In a Different Voice» publicado en 1982 quien abre de forma definitiva el debate contemporáneo entre feminismo y teoría moral $1^{30}$. En él, la autora presenta los resultados obtenidos en sus investigaciones sobre la diferencia entre el desarrollo del juicio moral femenino y masculino. Fueron básicamente tres investigaciones: un estudio realizado con mujeres sobre la decisión de abortar; un segundo trabajo con estudiantes de universidad en el que se relacionaba la autoimagen con experiencias de conflicto moral y un tercero sobre derechos y responsabilidades. Gilligan pretende demostrar la existencia de dos modos de comprender y hablar sobre temas morales, dos modos de describir la relación entre el yo y el otro, dos modos distintos de pensar sobre lo moral. Gilligan acusa a la psicología y a las distintas teorías del desarrollo humano (Freud, Piaget y Kohlberg) de estar profundamente masculinizadas, adoptando como norma absoluta las formas de vida, experiencias y modos de actuar y pensar del varón, y juzgando a las mujeres en función del patrón y de los niveles de desarrollo masculinos. En concreto, respecto al pensamiento moral afirma que «hay una concepción moral distinta a la descrita por Freud, Piaget o Kohlberg». En la concepción moral derivada del estudio de las mujeres el problema moral se aprecia cuando hay un conflicto entre distintas responsabilidades, haciéndose necesario un modo de pensar prioritariamente contextualizado y narrativo. El desarrollo moral, por tanto, no se puede definir en el caso de la mujer teniendo como criterio prioritario la justicia o imparcialidad sino la comprensión de la responsabilidad y las relaciones. Es por este motivo que ante un mismo dilema moral, los niños y las niñas perciben problemas distintos. La percepción masculina de los conflictos morales queda sobradamente recogida en la teoría de Kohlberg, pero ello no ocurre con la percepción femenina. Eso es lo que lleva a Gilligan a reclamar una nueva línea de interpretación del juicio moral y a determinar las fases sucesivas en esa línea femenina. A partir de los tres estudios empíricos realizados, Gilligan define los rasgos esenciales de los dos modelos de juicio moral. El modelo femenino se caracteriza por estar centrado en la moral «de la atención» o del cuidado mutuo. Las relaciones personales y la conexión humana son, según Gilligan, aspectos muy relevantes en el juicio moral femenino. El interés por los demás y el deseo de no dañar a nadie pueden justificar excepciones a la regla, si la situación así lo requiere. Los sentimientos de piedad hacia los demás priman sobre el valor de la normativa general y su aplicación imparcial. Asimismo en el caso de las mujeres nos encontramos ante un juicio moral contextual y narrativo, atento a la complejidad de cada circunstancia y a las situaciones personales.

A diferencia del modelo anterior, en el caso de los varones el juicio moral está presidido por el ideal de justicia. La igualdad, la imparcialidad y el sentido del deber facili-

30. Gilligan, C. (1985), La moral y la teoría. Psicología del desarrollo femenino. México, Fondo de Cultura Económico. Gilligan, C.; Largdale, S.; Lion, S. N. \& Murphy, M. (1982), The contribution of women's thought to development theory. The elimination of sexbias in moral development research and education. Cambridge, Harvard University. 
tan un juicio moral formal y abstracto pero poco atento a las situaciones concretas y a los contextos en que éste se aplica. Las situaciones no se analizan ya desde la red de relaciones y afectos personales existentes sino desde las relaciones sociales, haciendo valer la lógica formal de la imparcialidad. Los sentimientos y el cuidado de los demás ceden prioridad en favor de criterios racionales, de la misma manera que la contextualización del juicio moral da paso a la universalidad del mismo. Por último el juicio moral masculino tiene mayor facilidad para analizar las situaciones a partir de enfoques jurídicos derivados de la ley. Las excepciones son desde este punto de vista difíciles de justificar, pues dificultan los ideales de justicia e igualdad.

A partir de la constatación de dos modos distintos de pensar sobre temas morales, Gilligan plantea la posibilidad de establecer una secuencia de desarrollo en el pensamiento moral basado en el cuidado y la atención. Es decir, una secuencia de desarrollo para mujeres paralela a la elaborada por Kohlberg. en ella Gilligan distingue tres fases. Una, la relación del yo con los demás se basa en la exclusiva atención al yo para garantizar la supervivencia. Dos, la relación del yo con los demás se basa en un nuevo entendimiento mutuo que se expresa con el concepto de responsabilidad. Tres, la relación del yo con los demás intenta equiparar la igualdad con la atención, la autosatisfacción con el cuidado, el egoísmo con la responsabilidad ${ }^{31}$.

Como conclusión de su investigación, la autora insinúa una cierta complementariedad entre la moral del deber y la del cuidado, entre el juicio moral masculino y el femenino. Si bien las aportaciones de Gilligan son sumamente interesantes y ponen de relieve aspectos poco tratados en la teoría de Kohlberg, éstas no han sido suficientes para rechazar la filosofía y psicología moral universalista ${ }^{32}$. A pesar de la obviedad de la diferencia entre hombres y mujeres en cuanto al modo «habitual» de plantearse los problemas morales (subrayamos el adjetivo «habitual» por entender que tanto la mujer puede establecer juicio morales basados en el deber y la imparcialidad, como el hombre puede producir juicios morales más atentos al cuidado mutuo, la ternura y la comunicación), decíamos que a pesar de lo obvio que puede resultar la diferencia entre el pensamiento habitual moral masculino y femenino, Gilligan no establece con claridad el origen de tal diferencia. Probablemente ésta se deba a la influencia del medio y la educación. En su intento de satisfacer las demandas que la sociedad hace a cada uno de ellos, los niños y niñas dan respuestas distintas, pero ambos se encuentran en un nivel convencional, buscando la aprobación externa y la coherencia con aquello que los demás esperan de ellos y ellas. Por tanto, nos atrevemos a decir que las fases propuestas por Gilligan son, en el fondo, una paráfrasis de los niveles preconvencional, convencional y postconvencional definidos por Kohlberg. La primera fase de Gilligan está basada en el egoísmo y la búsqueda de beneficio (nivel preconvencional); la segunda fase se basa en el acuerdo con la sociedad, incluso cuando la demanda de ésta sea distinta en el caso del niño que en el de la niña (nivel convencional); la tercer y última fase se centra en la búsqueda de principios de conciencia, que en el caso de las niñas consiste en resolver para ellas mismas el dilema de responsabilidad (o sacrificio) respecto a los demás o desarrollo personal (nivel postconvencional).

31. Gilligan, C. (1985), La moral y la teoría. Psicología del desarrollo femenino. México, Fondo de Cultura Económico, p. 128.

32. Benhabib, S., «Una revisión del debate sobre las mujeres y la teoría moral», en ISEGORIA, nº 6, noviembre 1992, p. 50. Camps, V. (1990), Virtudes públicas. Madrid, Espasa, p. 159. 
Pensamos que la aportación de Gilligan debe servir, ante todo, para enriquece la teoría del desarrollo moral de Kohlberg, pero no para establecer barreras insalvables entre pensamiento moral femenino y masculino. Para ello parece evidente la defensa de la complementariedad entre puntos de vista morales. Y ello porque a partir de los estudios de Kohlberg y Gilligan se han puesto de manifiesto cualidades distintas de la persona moralmente educada. Mientras Kohlberg enfatiza la capacidad de juicio moral abstracto, racional y general, Gilligan subraya el pensamiento contextual y el valor del sentimiento, del cuidado por no dañar, de la responsabilidad hacia los demás. Ambas, razón y sentimiento, son cualidades deseables para todas las personas y prescindir del cultivo de alguna de ellas sólo puede generar personas moralmente inmaduras e incompletas.

De hecho el mismo Kohlberg responde a las críticas emitidas por Gilligan a su propuesta universal de desarrollo del juicio moral. En su respuesta Kohlberg intenta unificar ambos aspectos, el de justicia y el de preocupación por los demás, en el marco de su teoría Kohlberg plantea la cuestión de si el principio de justicia (entendido como igual respeto por la integridad de cada individuo) no incluye también aspectos tales como el de la preocupación por los demás y el de la felicidad concreta; aspectos que solamente desde un punto de vista simplista y superficial quedarían desvinculados del principio de justicia. En síntesis, Kohlberg relativiza la idea de justicia excesivamente centrada en el aspecto de la imparcialidad y la complementa con el principio de la benevolencia ${ }^{33}$ que se traduce en actitudes tales como la preocupación por el otro, la comprensión, y la disponibilidad para ayudar. Es así como justicia y benevolencia, a pesar de poderse diferenciar, derivan ambas de un principio común de orden superior que se corresponde con el principio que manda guardar el mismo respeto por la dignidad de cada persona y que está estrechamente vinculado al imperativo categórico de Kant. Kohlberg establece asimismo otra similitud entre el principio de justicia y el de benevolencia por cuanto ambos se entienden como resultado del procedimiento de la adopción de roles. Posteriormente Habermas modifica el principio de benevolencia y considera que debe ser sustituido por el principio de solidaridad, principio que tiene su raíz en el sentimiento de responsabilidad respecto a los demás ${ }^{34}$. Ambas perspectivas, razón y sentimiento deben considerarse en el modelo de educación moral que proponemos.

\section{Del «laboratorio» al medio cultural: la contextualización del juicio moral}

Un segundo elemento que con frecuencia se nota a faltar en las teorías cognitivas del desarrollo moral es la importancia que el contexto o el entorno ejercen en el juicio y pensamiento moral. El énfasis de Kohlberg en el razonamiento y la argumentación a propósito de situaciones moralmente conflictivas, así como sus mismas investigaciones en donde a los sujetos se les planteaba narraciones o dilemas fuertemente descontextualizados, pone de manifiesto el papel que las capacidades y desarrollo personal ejercen en el

33. Modgil, S. \& Modgil, C. (comps.) (1985), Lawrence Kohlberg. Consensus and Controversy. Philadelphia, Falmet Press, pp. 504-542.

34. Habermas, J. (1991), «Justicia y solidaridad (Una toma de posición en la discusión sobre la etapa 6 de la teoría de la evolución del juicio moral de Kohlberg) en Apel, K. O.; Cortina, A.; De Zan, J. y Michelini, D. (comps.), Etica comunicativa y democracia. Barcelona, Crítica, p. 198. 
razonamiento moral, pero tiende a olvidar que el juicio y la acción se producen siempre en un medio concreto ${ }^{35}$.

El pensamiento moral que se produce en un contexto concreto no siempre coincide con el juicio moral elaborado en una situación «de laboratorio», es decir, en una situación diseñada para producir argumentos. Es por ello que el pensamiento formal se debe complementar con otros elementos. Uno de los elementos claves es, probablemente, la presencia de contenidos abundantes y conocidos. Cuanto mayor y más significativa sea la información de que se dispone, el juicio moral es más complejo y elaborado. Los elementos a tener en cuenta se multiplican y obligan al sujeto a tener presentes datos que en otro momento ignoraba, favoreciéndole la reflexión y facilitándole en la medida de lo posible la coherencia entre el pensamiento y la conducta. Un segundo elemento que ayudará a enriquecer el juicio moral es la vinculación de éste a la acción moral. La tendencia existente a ignorar la significación de la experiencia activa en la génesis de los procesos cognitivos acentúa la separación teórica de ambos elementos, cuando en la práctica se dan, por normal general, de forma simultánea ${ }^{36}$. Insistir en el razonamiento al margen de la conducta lleva a obviar los niveles de experiencia con que ésta enriquece el pensamiento y lo modifica. El sentimiento de responsabilidad que la acción genera es imposible transferirlo a situaciones hipotéticas o descontextualizadas, en donde el pensamiento se puede producir sin que se dé una implicación personal ni se asuman las consecuencias de la solución propuesta. Las investigaciones llevadas a cabo por Kohlberg ignoraron en gran medida la información que la persona adquiere cuando actúa y cuando se ve obligada a asumir las consecuencias de sus opciones. Todo ello introduce un tercer elemento: el contexto cultural en donde se produce el razonamiento moral. El colectivo, los individuos que rodean a la persona, las instituciones, en definitiva todo lo humano se ve atravesado por un conjunto de valores que presionan sobre el juicio moral individual. La relativa neutralidad con que un individuo se puede enfrentar a un conflicto moral descontextualizado es prácticamente imposible cuando éste lo hace a propósito de una situación conocida, encarnada en un entorno cultural concreto y cuya solución le afectará personalmente. Por último, el pensamiento o razonamiento moral contextualizado se complica por cuanto es siempre un pensamiento interpsicológico. En él aparecen puntos de vista, necesidades, sentimientos, intereses, miedos y anhelos diferentes y frecuentemente confrontados.

\section{Relación entre juicio moral y acción moral}

Un tercer elemento, íntimamente ligado con los anteriores y nada fácil de resolver desde posiciones cognitivas, es el que hace referencia a la acción moral. La coherencia

35. Carretero, M.; Pozo, J. I. y Asensio, M. (1989), «Problemas y perspectivas en la enseñanza de las Ciencias Sociales: una concepción cognitiva», en Carretero, M.; Pozo, J. I. y Asensio, M.: La enseñanza de las ciencias sociales. Madrid, Visor, pp. 13-29. Coll, C. (1987), «La importancia de los contenidos en la enseñanza» en Investigación y escuela, $\mathrm{n}^{\circ} 3$, pp. 19-29. Newman, D.; Griffin, P. y Cole, M. (1991), La zona de construcción del conocimiento. Madrid, Morata, Ministerio de Educación y Ciencia.

36. Lave, J. (1991), La cognición en la práctica. Barcelona, Paidós, p. 192. 
entre juicio y acción moral es un aspecto que ha preocupado a los teóricos del tema y cuya relación no parece todavía clara ni mucho menos formulada de forma definitiva. Si bien Kohlberg no desatendió el aspecto conductual ${ }^{37}$, han sido otros autores quienes han llevado a cabo un mayor número de investigaciones destinadas a analizar la relación entre ambos elementos.

Kohlberg, ante las acusaciones que recibió su teoría por el hecho de basarse en situaciones hipotéticas y artificiales que podían distar notablemente de las acciones realizadas por los individuos en la vida real, afirmó que los juicios que establecen las personas respecto a casos hipotéticos tienen cierta correlación con las acciones llevadas a cabo por los mismos sujetos en situaciones reales. Afirmó asimismo que la consistencia entre juicio y acción moral aumenta progresivamente en la medida en que el individuo avanza de un estadio a otro. Según estas afirmaciones las acciones de los sujetos cuyo juicio moral se encuentra predominantemente en estadios postconvencionales son más coherentes con los juicios que emiten que las de aquellos individuos situados en estadios inferiores. Sin embargo, y a pesar de la importancia que el juicio moral puede tener en la acción moral, no es éste el único elemento que la determina. El juicio moral es, por tanto, una condición necesaria pero no suficiente para la acción moral.

Junto al juicio moral, la acción moral necesita de otra serie de factores para producirse, factores que no son estrictamente morales, pero sin los cuales difícilmente puede darse un comportamiento coherente con el pensamiento del individuo. Tal es el caso de la capacidad de la persona para el autocontrol ${ }^{38}$. En la medida en que el sujeto puede controlar la satisfacción inmediata de sus necesidades y contrarrestar aquellas demandas que provienen de la presión de las normas heterónomas, mayor posibilidad hay para que lleve a cabo aquello que considera justo y correcto ${ }^{39}$. Las investigaciones realizadas por distintos autores, en concreto por Blasi, señalan como los individuos que se encuentran en estadios superiores son menos influenciables a los factores situacionales y más propensos a actuar coherentemente con sus valores ${ }^{40}$. Tales sujetos asumen con mayor frecuencia las consecuencias que se derivan de sus juicios que los individuos que se encuentran en niveles inferiores. Son precisamente las consecuencias previstas por el sujeto, las que tienden a modificar considerablemente la realización de la conducta coherente con el razonamiento moral.

$\mathrm{Al}$ estudio de tal relación, juicio-acción moral, Blasi ha dedicado parte de sus investigaciones tras las cuales el autor reafirma la hipótesis de que razonamiento y acción moral están relacionados estadísticamente, si bien en unos aspectos la relación es más

37. Kohlberg, L. (1992), «Relación del juicio moral con la acción moral» en Kohlberg, L., Psicología del desarrollo moral. Bilbao, Desclée de Brower, pp. 463-533.

38. El modelo propuesto por Bandura sobre la autorregulación sería una aportación encaminada al trabajo específico sobre la conducta moral y la coherencia con aquello que el individuo desea realizar y valora de forma positiva. Bandura, A. (1987), Pensamiento y acción. Barcelona, Martínez-Roca.

39. Escámez, J., «Relación del conocimiento moral con la acción moral: la educación para una conducta moral» en Jordán, J. A. y Santolaria, F. (eds.) (1987), La educación moral, hoy. Cuestiones y perspectivas. Barcelona, PPU, pp. 207-240.

40. Blasi, A., «Las relaciones entre el conocimiento moral y la acción moral: una revisión crítica de la literatura» en Turiel, E.; Unesco, I. y Linaza, J. (1989), El pensamiento moral en la mente infantil. Madrid, Alianza, Psicología, pp. 331-388. 
intensa que en otros. Sin embargo, ello no implica que la conducta sea previsible a partir del juicio moral. Blasi considera que los rasgos personales que permanecen al margen de las estructuras cognitivas y de razonamiento moral ejercen una influencia importante en la acción. De igual modo existen fuentes motivacionales no cognitivas que interactúan con el razonamiento moral facilitando o inhibiendo una conducta concreta. Son motivaciones que no siempre aparecen en el razonamiento moral, pero que sí son tenidas en cuenta en el momento de llevar a cabo una acción concreta. A juicio del autor las teorías cognitivas y evolutivas han tendido a estudiar el razonamiento moral y los procesos cognitivos como fenómenos aislados del contexto psicológico, siendo precisamente en la naturaleza psicológica de la persona donde se encuentran los factores que se interponen entre juicio y acción moral. El conocimiento de estos principios no sólo facilitaría la comprensión del fenómeno moral, sino que enriquecería las aportaciones que desde las teorías evolutivo-cognitivas se han dedicado al tema.

\section{ÉTICA DIALÓGICA Y TEORÍA COGNTIVA DEL DESARROLLO: COHERENCIA Y FUNDAMENTA- CIÓN CONJUNTA DE LA EDUCACIÓN MORAL}

Para fundamentar el modelo de educación moral que proponemos, hemos partido de un paradigma filosófico concreto: las éticas dialógicas, y lo hemos sometido a diversas críticas que en la medida en que resaltaban las carencias o limitaciones del paradigma, han ayudado a complementarlo y enriquecerlo. En realidad, tales críticas no se han definido por oposición a las éticas dialógicas, ni ha sido su pretensión negarlas. Su función es, prioritariamente, ayudar a desarrollar el paradigma dialógico en nuevos ámbitos, es decir, hacer de él una teoría más completa y compleja. Por tanto, podemos afirmar que partimos del paradigma filosófico de la ética discursiva, añadiéndole, sin embargo, tres aportaciones-críticas: la recuperación del papel de los sentimientos morales en el ámbito moral; la construcción de criterios morales contextuales que se deriven de los principios morales universales, y la vinculación de la ética de principios a la ética de actitudes.

De manera semejante ha ocurrido en el ámbito de la psicología. El punto de partida ha sido la teoría cognitiva del desarrollo moral. Las críticas que ésta ha recibido desde diferentes enfoques y sensibilidades, han ayudado a mejorarla y optimizarla. Después de analizar dichas aportaciones, las consideramos, junto con la teoría de Kohlberg, parte del paradigma psicológico. Así, desde el punto de vista psicológico partimos de las teorías del desarrollo del juicio moral; de la recuperación del papel de los sentimientos, las emociones, $y$, en general de la vertiente afectiva del individuo; de la importancia del contexto y el entorno en el juicio moral; y de una mayor sensibilidad al aspecto de la acción moral y al conocimiento de aquellos elementos que la determinan. Dada la similitud y coherencia existente entre la ética discursiva y la teoría cognitiva del desarrollo moral, podemos ver como las críticas a una y a la otra han sido también semejantes, y parecida es también la propuesta de complementariedad e integración de los aspectos que hemos analizado. 


\begin{tabular}{|c|c|c|}
\hline & Etica discursiva & Psicología cognitiva \\
\hline Tesis & $\begin{array}{l}\text { Una norma sólo será aceptada si } \\
\text { se ha conseguido gracias a un } \\
\text { acuerdo racionalmente motiva- } \\
\text { do, producido en una situación } \\
\text { ideal de diálogo. }\end{array}$ & $\begin{array}{l}\text { Existe un desarrollo natural en } \\
\text { el pensamiento moral que se } \\
\text { lleva a cabo en estadios progre- } \\
\text { sivos e independientes de la } \\
\text { cultura. Este desarrollo conduce } \\
\text { hacia un juicio justo basado en } \\
\text { la plena capacidad para el role- } \\
\text { taking. }\end{array}$ \\
\hline emotividad & $\begin{array}{l}\text { Los sentimientos y emociones } \\
\text { morales son básicos en el desa- } \\
\text { rrollo de las capacidades para } \\
\text { percibir y reconocer problemas } \\
\text { morales, desempeñando por ello } \\
\text { un importante papel en la consti- } \\
\text { tución del fenómeno moral. Vin- } \\
\text { culación entre Emotivismo y } \\
\text { Racionalismo. }\end{array}$ & $\begin{array}{l}\text { Complementariedad entre pun- } \\
\text { tos de vista morales: moral del } \\
\text { deber y moral del cuidado. Ne- } \\
\text { cesidad de atender tanto la ca- } \\
\text { pacidad de juicio moral, } \\
\text { abstracto y racional como los } \\
\text { sentimientos de responsabilidad } \\
\text { y cuidado hacia los demás. }\end{array}$ \\
\hline contexto & $\begin{array}{l}\text { Necesidad de crear normas mo- } \\
\text { rales contextualizadas y referi- } \\
\text { das a las condiciones de vida } \\
\text { reales de los distintos grupos e } \\
\text { individuos, que se deriven de los } \\
\text { principios universales éticos. }\end{array}$ & $\begin{array}{l}\text { Variación entre los juicios hipo- } \\
\text { téticos y los juicios contextuali- } \\
\text { zados. La implicación en el } \\
\text { problema y asumir las conse- } \\
\text { cuencias derivadas de la opción, } \\
\text { modifica considerablemente el } \\
\text { juicio moral. }\end{array}$ \\
\hline acción & $\begin{array}{l}\text { El paradigma dialógico lleva im- } \\
\text { plícita una propuesta de conduc- } \\
\text { tas, hábitos y virtudes, en } \\
\text { definitiva, un «ethos» moral, } \\
\text { dialógico, democrático y univer- } \\
\text { sal. Junto a él deben integrarse } \\
\text { las capacidades de auto direc- } \\
\text { ción del sujeto }\end{array}$ & $\begin{array}{l}\text { Existencia de fuentes motiva- } \\
\text { cionales y rasgos de personali- } \\
\text { dad que interactúan con el } \\
\text { juicio moral facilitando o inhi- } \\
\text { biendo una conducta. }\end{array}$ \\
\hline
\end{tabular}

Consideramos que a partir de esta síntesis podemos definir algunos de los principales aspectos o dimensiones que debe atender la educación moral. Entendemos pues, que una educación preocupada por la formación de personalidades morales adultas deberá ser sensible no sólo a un correcto desarrollo del juicio moral sino también al tema de las emociones y los sentimientos morales, deberá preocuparse asimismo por ayudar a los individuos a contextualizar el juicio moral, valorando las circunstancias y situaciones en que se produce el conflicto, y por último deberá trabajar la acción o conducta moral, evitando distancias insalvables entre ésta y el razonamiento moral. 